\title{
Transient Allodynia Following Caudal Lipoma Excision: A Case Report
}

\author{
Orhan Kalemci', Ercan Ozer ${ }^{1}$, Kemal Yucesoy ${ }^{1}$, Mehmet Nuri Arda1, Yüksel Erkin² \\ 'Department of Neurosurgery, Dokuz Eylül University Medical Faculty, Inciralti, Izmir, Turkey \\ ${ }^{2}$ Department of Anaesthesiology and Reanimation, Dokuz Eylül University Medical Faculty, Inciralti, Izmir, Turkey
}

\begin{abstract}
Allodynia is the sensation of pain due to non-painful stimuli. It usually occurs due to destructive lesions of the spinal cord or peripheral nerves. Allodynia following intradural lipoma surgery has been reported previously. We herein report a case of allodynia developed after microsurgical caudal lipoma excision without associated spinal cord injury.
\end{abstract}

Key Words: Hyperalgesia, Caudal lipoma surgery

\section{Introduction}

Allodynia is caused by low intensity non-painful stimuli [1]. It usually occurs due to destructive lesions of the spinal cord or peripheral nerves, and patients usually sustain major neurologic deficits [2-4]. We herein report a case of allodynia caused by caudal lipoma surgery without associated spinal cord injury.

\section{Case Report}

A 26-year-old man was admitted to our clinic with history of severe back and left leg pain. Neurological examination revealed mild plantar flexion deficit, absent Achilles reflex and positive Lasègue sign on the left. Magnetic resonance imaging (MRI) showed an extruded discal herniation at the level of L5-S1 on the left, and an intradural caudal lipoma (Fig. 1). We performed microsurgical subtotal lipoma excision after L5-S1 discectomy in one session. The lipoma operation was uneventful, and surgical microscope was used throughout all excision steps. The lipoma was removed partially because of adhesion to the conus medullaris. During general anesthesia recovery, the patient complained of severe burning pain in his lower extremities that increased with painless stimuli. Pain was more prominent on the right and below the knees bilaterally. Also, the patient could not move both lower extremities due to induced pain. Analgesia did not relieve his symptoms. Eventually, high dose $(250 \mathrm{mg} /$ day $)$ meperidine and gabapentine ( $400 \mathrm{mg} /$ day t.d.s.) were given after Pain Clinic consultation. His symptoms resolved totally two weeks after the operation without neurological sequelae.

\section{Discussion}

Neuropathic pain, whether of peripheral or central origin, is characterized by neuronal hyperexcitability in the damaged areas of the nervous system. Sensory dysfunction may manifest itself as hypoesthesia or hyperesthesia. In the case of hyperesthesia, increased pain to painful stimuli is known as hyperalgesia and as allodynia to non-painful stimuli. Membrane stabilizing agents such as anticonvulsants, antiarrhythmics, corticosteroids, and agents that enhance dorsal

Received Aug 12, 2010; 1st Revised Dec 25, 2010; Accepted Dec 27, 2010

Corresponding author: Orhan Kalemci, MD

Department of Neurosurgery, Dokuz Eylül University Medical Faculty,

DEÜTF Nöroşirurji AD 35340, Inciralti, tzmir, Turkey

Tel: +90-232-4123305, Fax: +90-232-2788802, E-mail: okalemci@ gmail.com 

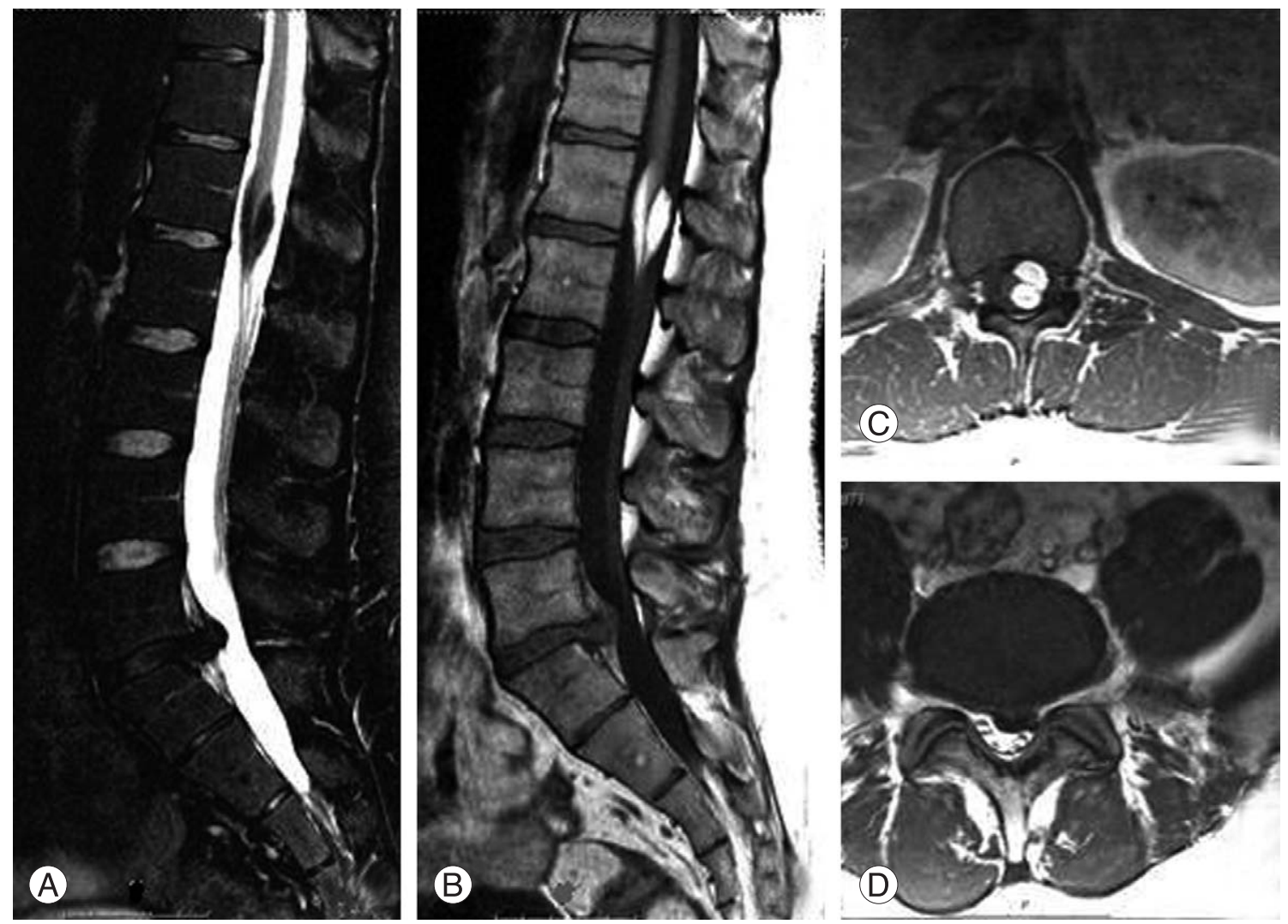

Fig. 1. Fat suppression and T1 weighted magnetic resonance (MR) sequences demonstrating intradural lipoma and L5-S1 disc herniation (A, B). Axial MR images at the level of the lipoma (C) and L5-S1 disc herniation (D).

horn inhibition such as anticonvulsants and antidepressants are used for the treatment of neuropathic pain [1].

Allodynia has been reported after spinal cord injury as a result of trauma [2], intrathecal morphine administration [3] and automated lumbar discectomy [4], but no case has been reported previously after intradural lipoma surgery [5]. In the existing reports, allodynia was always seen following spinal cord injury and associated with resultant neurological deficits [2-5]. We performed intradural lipoma operation microsurgically without incurring injury to spinal cord in our patient. Allodynia developed despite the absence of spinal cord injury and that is inconsistent with the reported cases in the literature. Also, because of the symptom free outcome without neurological sequelae, allodynia might have been secondary to chemical irritation of the conus medullaris or cauda equina with fat particles in our patient. Ectopic activity and $\mathrm{Na}^{++}$and $\mathrm{Ca}^{++}$channel opening may cause neuropathic pain [6]. High concentration of polyunsaturated free fatty acids in the cerebrospinal fluid obtained from patients on ketogenic diet has been shown to activate voltage gated $\mathrm{K}^{+}$channels. Microtrauma to the cord may initiate neuropathic pain, and activation of $\mathrm{K}^{+}$channels may prevent repolarization and sustain neuropathic pain for some time [7].

Allodynia may be seen following spinal intradural caudal lipoma surgery without associated spinal cord injury. Fat particle irritation may be the cause and the resultant symptom free recovery without neurological sequelae.

\section{REFERENCES}

1. Bulsara KR, Zomorodi AR, Villavicencio AT, Fuchs H, George TM. Clinical outcome differences for lipomyelomeningoceles, intraspinal lipomas, and lipomas of the filum terminale. Neurosurg Rev 2001;24:192-4.

2. Haller H, Leblhuber F, Trenkler J, Schmidhammer R. Treatment of chronic neuropathic pain after traumatic central cervical cord lesion with gabapentin. J Neural Transm 2003;110:977-81.

3. Orza F, Boswell MV, Rosenberg SK. Neuropathic pain: review of mechanisms and pharmacologic management. NeuroRehabilitation 2000;14:15-23.

4. Parisod E, Siddall PJ, Viney M, McClelland JM, Cousins MJ. Allodynia after acute intrathecal morphine administra- 
tion in a patient with neuropathic pain after spinal cord injury. Anesth Analg 2003;97:183-6.

5. Plancarte R, Calvillo O. Complex regional pain syndrome type 2 (causalgia) after automated laser discectomy: a case report. Spine (Phila Pa 1976) 1997;22:459-61.

6. Bridges D, Thompson SW, Rice AS. Mechanisms of neu- ropathic pain. Br J Anaesth 2001;87:12-26.

7. Xu XP, Erichsen D, Börjesson SI, Dahlin M, Amark P, Elinder F. Polyunsaturated fatty acids and cerebrospinal fluid from children on the ketogenic diet open a voltagegated K channel: a putative mechanism of antiseizure action. Epilepsy Res 2008;80:57-66. 